\title{
Electrospun polylactic acid/date palm polyphenol extract nanofibres for tissue engineering applications
}

\author{
Khadija M. Zadeh ${ }^{1}$ - Adriaan S. Luyt ${ }^{1}$ - Lubna Zarif ${ }^{2} \cdot$ Robin Augustine $^{2,3} \cdot$ Anwarul Hasan $^{2,3} \cdot$ Massimo Messori $^{4}$. \\ Mohammad K. Hassan ${ }^{1}$ (D) Huseyin C. Yalcin ${ }^{2}$
}

Received: 5 March 2019 / Accepted: 10 July 2019 / Published online: 26 July 2019

(C) The Author(s) 2019

\begin{abstract}
In this study, a set of polylactic acid (PLA)/polyphenol extracted from date palm fruit (DP) blends were prepared by electrospinning process to be used as cell culture scaffolds for tissue engineering applications. For this purpose, PLA/DP blends with variable composition were dissolved in dichloromethane/dimethylformamide $(70: 30, v / v)$ mixture and then electrospun to obtain the fibres. Contact angle measurements, dynamic mechanical analysis, mechanical tensile and scanning electron microscopy (SEM) tools were used to study the physico-mechanical properties of the electrospun scaffolds. The results revealed that scaffolds became more hydrophilic with addition of DP. Increasing the polyphenol concentration caused the tensile strength and Young's modulus to decrease. The SEM graphs indicated a decrease in fibre diameter with increasing DP content. In addition, it was found that both cell proliferation and cell viability were enhanced with increased DP concentration within the scaffolds. The scratch test shows that there is an enhancement in cell migration through the scratch for PLA/DP scaffolds; again, higher DP content resulted better migration. Our results suggest that improved mechanical properties, decreased fibre diameter and enhanced hydrophilicity with addition of DP improved cell migration and cell adhesion for the scaffolds. Overall, these results demonstrate that DP is a potential natural cell-friendly product for tissue engineering applications such as tissue regeneration or wound healing assays.
\end{abstract}

Keywords Date palm fruit · Polylactic acid/polyphenol blend · Electrospinning $\cdot$ Scaffold $\cdot$ Cell adhesion $\cdot$ Tissue engineering

\section{Introduction}

Tissue engineering (TE) combines cells, materials and appropriate biochemical factors to produce live tissues that would replace degenerative tissues. Despite the significant potential applications, developments in this field are far beyond the expectations and there are only few tissue-engineered

Mohammad K. Hassan

mohamed.hassan@qu.edu.qa

Huseyin C. Yalcin

hyalcin@qu.edu.qa

1 Center for Advanced Materials, Qatar University, PO Box 2713, Doha, Qatar

2 Biomedical Research Center, Qatar University, PO Box 2713, Doha, Qatar

3 Department of Mechanical and Industrial Engineering, Qatar University, PO Box 2713, Doha, Qatar

4 Department of Engineering “Enzo Ferrari”, University of Modena and Reggio Emilia, Via Pietro Vivarelli 10/1, 41125 Modena, Italy products in the market [1]. One important component in TE is the selection of appropriate biomaterial for scaffold production that would not be rejected by the immune system once implanted to the host. Thus, many researchers work on techniques to promote tissue regeneration in biological environments [2]. The process requires overcoming inhibitory factors and promoting cell adhesion and cell proliferation to make the engineered tissue functional. Usually, biodegradable scaffold materials are selected to enhance tissue regeneration for replacing the synthetic biomaterial with the extracellular matrix (ECM) produced by the cells [3]. Another major challenge is the formation of reactive oxygen species (ROS) on the surfaces of transplanted biomaterial scaffolds [4]. In the body, ROS forms as a by-product of normal oxygen metabolism and is associated with important roles in cell signalling, wound healing and inflammatory responses. ROS oxidizes and releases molecules such as hydrogen peroxide $\left(\mathrm{H}_{2} \mathrm{O}_{2}\right)$, superoxide anions $\left(\mathrm{O}^{-2}\right)$ and free radicals including hydroxyl $\left(\mathrm{OH}^{*}\right)$ and peroxy $\left(\mathrm{R}-\mathrm{COO}^{\circ}\right)$, which are usually short-lived and highly reactive inside the body. During diseased states such as inflammation, diabetes and cancer, ROS levels can 
increase dramatically which can damage the structure of the cells [5]. Thus, the use of antioxidant materials blended with biomaterials is an essential strategy in TE to prevent excessive ROS production, which might trigger inflammation and eventual rejection of the implant.

Along with other biodegradable polymers such as polycaprolactone (PCL) [6] and polyvinyl alcohol (PVA), polylactic acid (PLA) is one of the most exploited scaffold material for TE applications [7, 8]. Recent investigations on PLA scaffolds have focused on the optimization of their cell adhesion properties [9]. For instance, Llorens et al. [10] studied the incorporation of different types of antioxidants on PLA electrospun fibre scaffolds and found that the addition of antioxidants enhanced the cell adhesion characteristics. Moreover, it has been reported within in vitro and in vivo settings that when antioxidants are provided, free radicals responsible for cell damage are attenuated which results in rapid wound healing due to enhanced proliferation [11]. Therefore, incorporation of polyphenol antioxidant to PLA scaffolds, as reported herein, is expected to improve biocompatibility of these scaffolds in TE applications. Polyphenols extracted from plants have been used as dietary antioxidants and recent investigations showed that these compounds provide protection against development of cancers, cardiovascular diseases, diabetes, osteoporosis and neurodegenerative diseases [12].

Several studies discussed the methods of polyphenol extraction from different plants such as green tea [13] and grapes [14]. Yanna et al. [15] investigated the antibacterial effect of different loadings of tea polyphenol on PLA electrospun nanofibres and showed enhanced antibacterial activity with addition of polyphenol. However, antibacterial activity gradually gets impaired when tea polyphenol content surpasses a certain level. Date palm is another plant containing polyphenols [16] and it is widely abundant in the Middle East [17].

Although there are several studies for the application of PLA scaffolds in TE [10], to best of our knowledge, there is no study that discussed the effect of the derived polyphenols from date palm fruit in PLA scaffolds. In this study, we introduce new electrospun nanofibre scaffolds made from PLA that was blended with polyphenol extracted from date palm fruits. The electrospun nanofibres were characterized for their physical, mechanical and morphological properties. In vitro biocompatibility tests were performed using NIH/3T3 fibroblast cells, since fibroblasts are the most abundant cells in skin tissue. MTT, live/dead and cell migration assays were performed for biological characterization. The aim of the present work is to demonstrate the potential benefits of incorporating polyphenol extracted from date palm fruit in PLA scaffolds for TE applications.

\section{Materials and methods}

\subsection{Materials}

The polylactic acid (PLA) used in this study is a high molar mass biopolymer (Ingeo ${ }^{\mathrm{TM}}$ Biopolymer 2003D) obtained from NatureWorks, LLC (USA). It is transparent with a density of $1.24 \mathrm{~g} \mathrm{~cm}^{-3}$ and melt flow index of $6.0 \mathrm{~g} / 10 \mathrm{~min}$ at $2.16 \mathrm{~kg} / 210^{\circ} \mathrm{C}$. Dimethyl formamide (DMF) (ACS, 99.8\%), gallic acid and sodium carbonate were purchased from Sigma Aldrich. Dichloromethane (DCM) with a density $133 \mathrm{~kg} / \mathrm{L}$ and Folin-Ciocalteu reagent were obtained from BDH Middle East LLC. All reagents were used as received without further purification.

\subsection{Polyphenol extraction from the data palm fruits}

Extraction of polyphenol from date palm fruits was conducted according to the steps shown in Fig. 1.
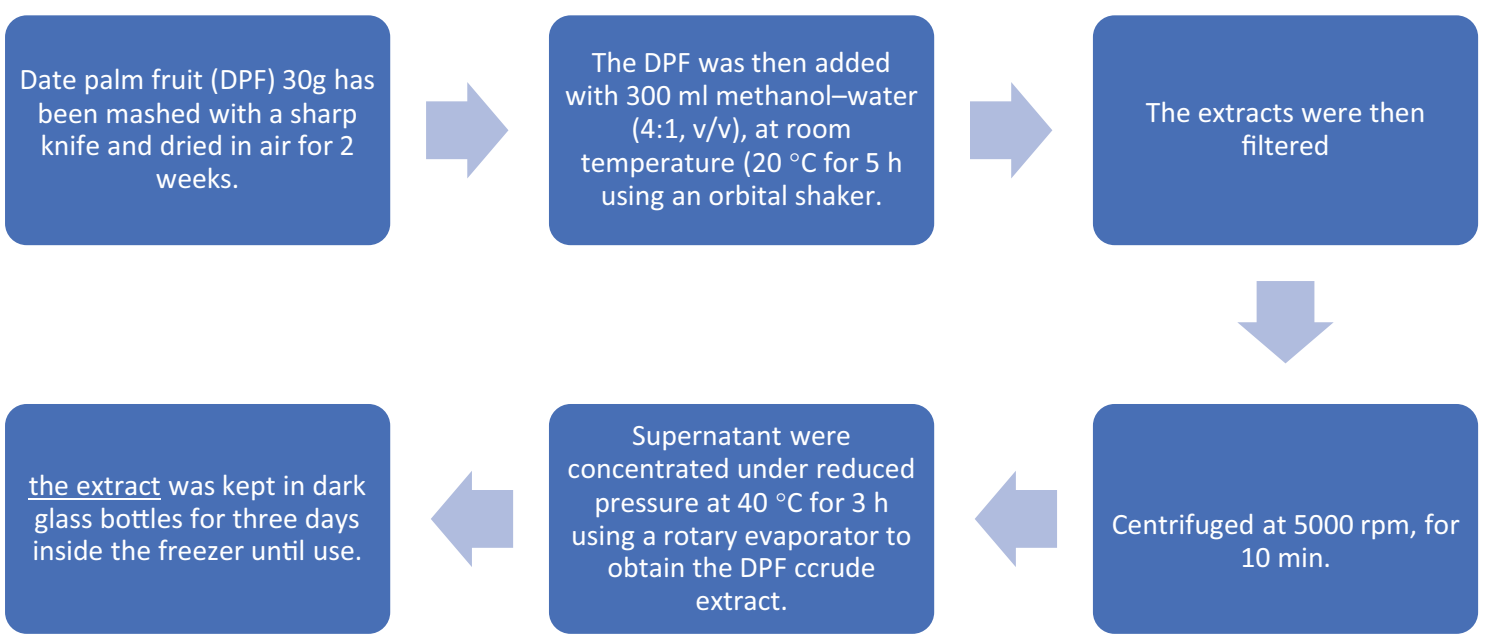

Fig. 1 The schematic diagram of polyphenol extraction methods from date palm fruits

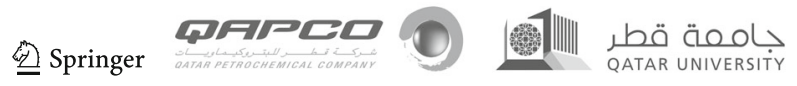




\subsection{Production of PLA/polyphenol blend by electrospinning}

$7 \mathrm{wt} \%$ PLA was dissolved in DCM:DMF mixture (70:30) for at least $3 \mathrm{~h}$ at room temperature. Polyphenol was then added to the PLA solution and the mixture was ultrasonicated for $20 \mathrm{~min}$. Three different sets were prepared with different polyphenol concentrations as shown in Table 1. The electrical conductivity of the solution was measured using a conductivity metre (Mettler Toledo S470). Viscosity and conductivity characteristics of the blends are summarized in Table 2.

Electrospun nanofibres were fabricated using $\mathrm{NaBond}$ electrospinning machine (Shenzhen, China). PLA suspensions were loaded into a $10-\mathrm{mL}$ syringe, with a bluntend, stainless steel needle 0.7. An aluminium foil covered rotating drum collector was used as the collection screen. The collector is connected to the ground electrode of the power supply and the distance between the screen and the needle tip was $15 \mathrm{~cm}$. The electrospinning process was conducted at room temperature at a voltage of $13 \mathrm{kV}$, flow rate of $0.8-1.5 \mathrm{~mL} / \mathrm{h}$ and drum speed of $500 \mathrm{rpm}$. The thickness of produced mats was around $50 \mu \mathrm{m}$.

\section{Characterization methods}

\subsection{Polyphenol characterizations}

\subsubsection{Total phenolic content}

The total phenolic content was determined using FolinCiocalteu reagents. Forty microliters of extract was mixed with $1.8 \mathrm{~mL}$ of Folin-Ciocalteu reagent (diluted with 10fold with distilled water) and the solution was kept at room temperature for $5 \mathrm{~min}$. Then, $1.2 \mathrm{~mL}$ of sodium carbonate solution $7.5 \mathrm{wt} \%$ was added to the mixture and the solution was kept at room temperature for $60 \mathrm{~min}$. The absorbance was then measured at $650 \mathrm{~nm}$ using a UV/VIS Biochrom spectrophotometer. The total polyphenol content was expressed as gallic acid equivalent (GAE)/100 $\mathrm{g}$ of the sample. For this step, a calibration curve was obtained with different concentrations of GA.

Table 1 The concentration of the blends

\begin{tabular}{lll}
\hline Sample & PLA (wt\%) & $\begin{array}{l}\text { Polyphenols } \\
\text { (wt\%) }\end{array}$ \\
\hline PLA & 100 & 0 \\
PLA/DP1 & 99 & 1 \\
PLA/DP5 & 95 & 5 \\
PLA/DP10 & 90 & 10 \\
\hline
\end{tabular}

Table 2 Viscosity and conductivity characteristics of the blends

\begin{tabular}{lll}
\hline Sample & $\begin{array}{l}\text { Viscosity } \\
(\mathrm{mPa} \mathrm{s})\end{array}$ & $\begin{array}{l}\text { Conductivity } \\
(\mu \mathrm{s} / \mathrm{cm})\end{array}$ \\
\hline PLA & 250 & 16.57 \\
PLA/DP1 & 195 & 16.87 \\
PLA/DP5 & 190 & 17.47 \\
PLA/DP10 & 184 & 21.9 \\
\hline
\end{tabular}

\subsection{Scanning electron microscopy}

The morphology of the electrospun fibres of PLA/polyphenol blends was inspected by a field emission scanning electron microscope (FE-scanning electron microscopy (SEM), Nova Nano SEM 650) at different magnifications. All specimens were sputter-coated with $2 \mathrm{~nm}$ gold before the use of the SEM.

\subsection{Porosity}

The porosity of the fabricated fibre mats was measured using the alcohol displacement method. The mats were immersed in $100 \%$ ethanol for $48 \mathrm{~h}$ until they were saturated and the percentage of porosity was calculated according to Eq. 1 below:

$P=(\mathrm{W} 2-\mathrm{W} 1) / \rho \mathrm{V} 1 \times 100$

Here, W1 and W2 are the weight of the mat before and after immersion in ethanol respectively, $\mathrm{V} 1$ is the volume of the mat before immersion in ethanol and $\rho$ is the density of ethanol, which equals to $789 \mathrm{~kg} / \mathrm{m}^{3}$.

\subsection{Contact angle measurements}

The hydrophilicity of the electrospun fibre mats was assessed by determining contact angles. Contact angle measurements were carried out with water using a DataPhysics contact angle system OCA 20 , in order to determine the changes in the hydrophilic character of pure PLA and its blend with different concentrations of polyphenol. Sample thicknesses of the fibre mats were $0.43 \mathrm{~mm}$. All measurements were carried out with water, and each sample was measured with a minimum of five drops.

\subsection{Tensile testing}

Samples were cut into 1-cm width and 10-cm length rectangular pieces and mechanical testing was conducted at room temperature using LF LLOYD INSTRUMENTS (An Ameter Company) at a crosshead speed of $5 \mathrm{~mm} / \mathrm{min}$. Three specimens were used for each sample and the reported values are the average of obtained results. 


\subsection{Dynamic mechanical analysis}

Effect of polyphenol loadings on the glass transition temperature (Tg) of PLA was studied using dynamic mechanical analyzer (DMA) (RSA-G2, TA Instruments, USA) in tensile mode. Rectangular specimens with dimensions of $15 \mathrm{~mm} \times 3 \mathrm{~mm} \times 0.05 \mathrm{~mm}$ were cut from the samples. Change in $\tan \delta$ and storage modulus vs. temperature was determined from the constant value of the elastic modulus on $0.1-200 \mu \mathrm{m}$ displacement and $30-100{ }^{\circ} \mathrm{C}$ temperature ranges at a heating rate of $5{ }^{\circ} \mathrm{C} / \mathrm{min}$ and a frequency of $1 \mathrm{~Hz}$. The specimens were subjected to a tensile deformation of $0.1 \%$.

\subsection{Cell line and culture conditions}

NIH/3T3 fibroblast cell line was obtained from the American Type Culture Collection (ATCC, USA). Cells were cultured using Dulbecco's Modified Eagle's Medium (DMEM) supplemented with 10\% FBS and $0.1 \%$ penicillin/streptomycin, inside a humidified $\mathrm{CO}_{2}$ incubator (Thermo Fisher Scientific, USA) at $5 \% \mathrm{CO}_{2}$ and $37{ }^{\circ} \mathrm{C}$ temperature. For biological assays, cells were cultured in either 6-well plates or 24-well plates until confluence. All the experiments were performed using cells with passages ranging from 15 to 20 . Initial concentrations of $1 \times 10^{5}$ cells/well for 6 -well plates and $5 \times$ $10^{4}$ cells/well for 24 -well plates were seeded to each well in the experiments. Cells were then incubated for $24 \mathrm{~h}$ in $\mathrm{CO}_{2}$ incubator until they reach full confluence at which point tested scaffolds were placed into cell culture wells. Scaffolds were sterilized by UV irradiation (20 min) prior to placement into wells containing cells. Cells were cultured in the presence of scaffolds for an additional $24 \mathrm{~h}$.

\subsection{Cell proliferation assay}

Cell proliferation was quantified with 3-(4,5-dimethylthiazol2-yl)-2,5-diphenyl-tetrazolium bromide known as MTT assay (Sigma, USA). This test indicates the number of viable cells and the level of metabolic activity of the cells in the presence of scaffolds [18]. For MTT assays, we cultured cells in 24-well plates. After incubation period with scaffolds $\left(24 \mathrm{~h}\right.$ in $\mathrm{CO}_{2}$ incubator), the medium and scaffolds were discarded. The cells were then rinsed in PBS twice. We then added $50 \mu \mathrm{L}$ of MTT solution ( $5 \mathrm{mg} / \mathrm{mL}$ in PBS) to each well and incubated for $4 \mathrm{~h}$. After the incubation period, the reaction was stopped by discarding solution (MTT and DMEM medium) and the converted dye was dissolved in dimethyl sulfoxide (DMSO) for $15 \mathrm{~min}$. Of the purple solution, $100 \mu \mathrm{L}$ was taken from each sample, transferred to a 96-well plate and subjected to optical density (OD) measurements of the converted dye, at a wavelength of $570 \mathrm{~nm}$ according to the manufacturer's instructions, using a EPOCH2 microplate reader (BioTek). To quantify the effect of scaffolds on cell proliferation, Eq. 2 was used as follows:

Cell proliferation $(\%)=($ OD of sample $/ O D$ of control $) \times 100$

All the experiments were repeated 3 times and absorbance was measured in triplicates.

\subsection{Live/dead assay}

A live/dead cell viability/cytotoxicity kit (Molecular Probes, USA) was used to visually evaluate the effect of scaffolds on cell viability. The live/dead stain was prepared by adding $5 \mu \mathrm{L}$ of ethidium homodimer-1 (EthD-1) and $5 \mu \mathrm{L}$ calcein $\mathrm{AM}$ to $10 \mathrm{~mL}$ serum-free medium (final concentrations of $1 \mu \mathrm{M}$ EthD-1 and $2 \mu \mathrm{M}$ calcein). Live cells convert calcein AM into green fluorescent calcein staining whole cytoplasm while EthD-1 penetrates through damaged membranes of dead cells and upon binding to nucleic acids produces a bright red fluorescence of the nucleus [19]. For live/dead assay, we used 6-well plates. After incubation period with scaffolds ( $24 \mathrm{~h}$ in $\mathrm{CO}_{2}$ incubator), the medium and scaffolds were discarded. The cells were rinsed in PBS twice and then were treated with prepared stains for $1 \mathrm{~h}$. Finally, the cells were visualized using an inverted fluorescence microscope at $\times 40$ magnification (OLYMPUS IX-71, UK) and images were captured by Zen imaging software using an Axiocam camera (Zeiss). From the obtained images, cell viability was calculated using Eq. 3 below:

Viability $(\%)=\mathrm{L} /(\mathrm{L}+\mathrm{D}) \times 100$

Here, $L$ and $D$ are the total number of visualized living and dead cells, respectively. Experiments were performed in triplicate for each experimental scaffold run.

\subsection{Cell migration assay}

Effect of PLA/polyphenol scaffolds on cell migration was determined by the scratch cell migration assay. The scratch was created in confluent cells on 6-well plate using a pipette tip. The cells were then rinsed with PBS to remove any freefloating cells and debris. Serum-free cell medium was then added, and culture plates were incubated at $37^{\circ} \mathrm{C}$ in the presence of scaffolds for $24 \mathrm{~h}$. Images of scratched areas were captured with an inverted microscope (Olympus IX-71, UK). Experiments were performed in duplicates for each scaffold.

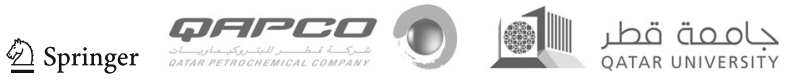




\section{Results and discussion}

\subsection{Total phenolic content}

The total phenolic compounds in date palm fruit are expressed as milligrammes of gallic acid equivalent in $100 \mathrm{~g}$ of fresh weight of the date fruit. The equation obtained from constructed plot of standard gallic acid was used to calculate the total phenolic content (line $A=\mathrm{mx}+C, R^{2}=0.98$ )

Here, $A$ is the absorbance and $C$ is the concentration as gallic acid equivalent $(\mathrm{mg} / \mathrm{mL})$. We found $2.5 \mathrm{mg} \mathrm{GAE} /$ $100 \mathrm{~g}$ of fresh weight, similar to the result reported for Algerian and Iranian date palm fruits [20], where it ranged from 2.49 to $8.36 \mathrm{mg} \mathrm{GAE} / 100 \mathrm{~g}$ of dry weight. The variation in total phenolic content is most likely due to factors such as maturity of the fruit and geographic origin.

\subsection{Morphology and hydrophilicity}

The surface morphologies of the electrospun fibres are shown in Fig. 2. It can be observed that continuous fibres were obtained successfully in both pure PLA and PLA blended systems. It is clear that the fibre diameter is affected by the addition of the polyphenol: as the polyphenol contents increases, the fibre diameter decreases. This is an expected finding since high solution viscosity of pure PLA has been associated with the production of larger fibre diameter [21]. Our observation is consistent with a recent study by Yanna et al. [22] who also found that addition of polyphenol extracted from tea resulted in decreasing the fibre diameter due to viscosity lowering. Related contact angles of fibre mats are also shown in Fig. 2, evaluated by Image $\mathrm{J}$ software. Both fibre diameter and contact angle decrease with increasing polyphenol content; while for pure PLA, the average fibre dimeter is $1.8 \mu \mathrm{m}$ and the contact angle is $140^{\circ}$, for PLA/DP10, the average fibre dimeter is $500 \mathrm{~nm}$ and the contact angle is $98^{\circ}$. These result show that the blend hydrophilicity increases and fibre diameter decreases with the increase in polyphenol concentration in the PLA.

\subsection{Porosity}

The porosity of the fabricated PLA/DP scaffolds was evaluated using the alcohol displacement method. As shown in Table 3, addition of polyphenol decreased the porosity. While pure PLA scaffold has $90 \%$ porosity, PLA/DP10 scaffold had $82 \%$ porosity.
Fig. 2 Electrospun fibres a pure PLA, b PLA/DP1, c PLA/DP5 and $\mathbf{d}$ PLA/DP10 with their corresponding contact angles
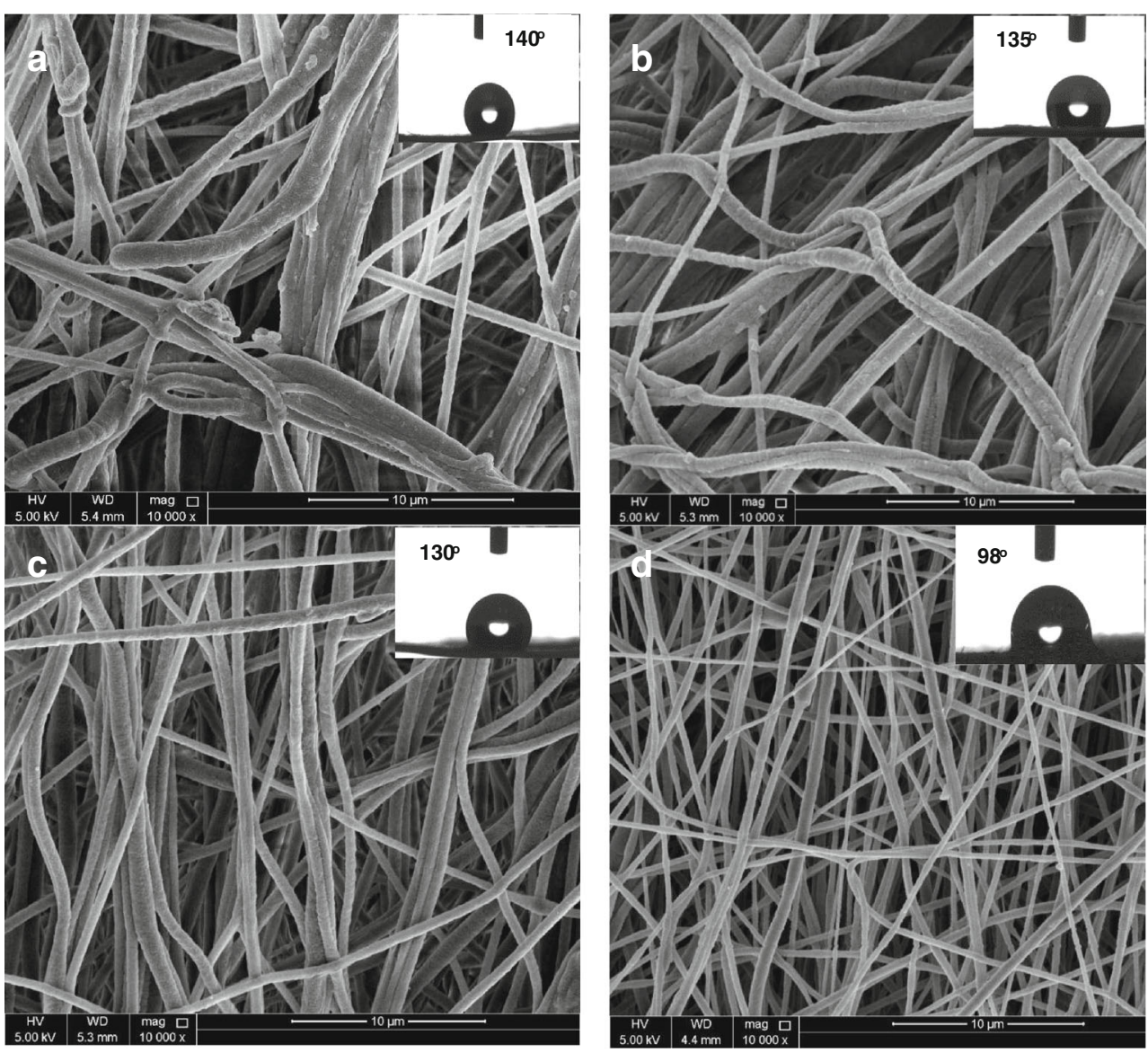

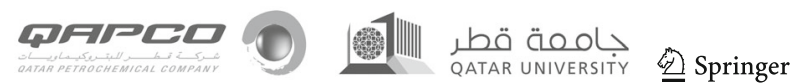


Table 3 Porosity percentages of PLA compared with blended systems

\begin{tabular}{ll}
\hline Sample & Porosity (\%) \\
\hline PLA & 90 \\
PLA/DP1 & 88 \\
PLA/DP5 & 85 \\
PLA/DP10 & 82 \\
\hline
\end{tabular}

\subsection{Mechanical properties}

Mechanical characterization of electrospun nanofibres was performed by tensile testing measurements and dynamic mechanical measurements. Table 4 represents the tensile strength, the Young modulus of elasticity and the percentage of elongation at break for pure PLA and the PLA/polyphenol blend samples.

\subsubsection{Tensile testing}

Tensile strength and Young's moduli of PLA/DP nanofibres were significantly lower compared with pure PLA. As the polyphenol concentration increases, both tensile strength and Young's Modulus decreased. The presence of polyphenol also resulted in lower elongations. The elongation at break of the blended systems was significantly lower than that of the pure PLA. The decreases in tensile strength resulted from the weakening or plasticization of the PLA molecular chain bonding which could explain the significant drop in the elongation at break values in the blends [23].

\subsubsection{Dynamic mechanical analysis}

The dynamic mechanical behaviour of the electrospun mats containing PLA/DP was measured in the broad temperature range as shown in Fig. 3. The damping properties of the material give the balance between the elastic and viscous phases in a polymeric structure [24]. Figure 4 shows an increase in the $\mathrm{Tg}$ peak broadening with addition of polyphenol. The $\mathrm{Tg}$ for the neat PLA was $67^{\circ} \mathrm{C}$ and did not change with polyphenol addition. The Tg broadening and intensity decrease could indicate some interactions between the hydroxyl groups of the

Table 4 Tensile testing results of pure PLA compared with different concentrations of polyphenols

\begin{tabular}{llll}
\hline & $\begin{array}{l}\text { Tensile strength } \\
(\mathrm{MPa})\end{array}$ & $\begin{array}{l}\text { Young's modulus } \\
(\mathrm{MPa})\end{array}$ & $\begin{array}{l}\text { Elongation } \\
\text { at break }(\%)\end{array}$ \\
\hline PLA & 10.4 & 632.3 & 11.6 \\
PLA/DP1 & 7.8 & 233.1 & 1.1 \\
PLA/DP5 & 3.1 & 188.2 & 0.5 \\
PLA/DP10 & 1.5 & 61.9 & 0.01 \\
\hline
\end{tabular}

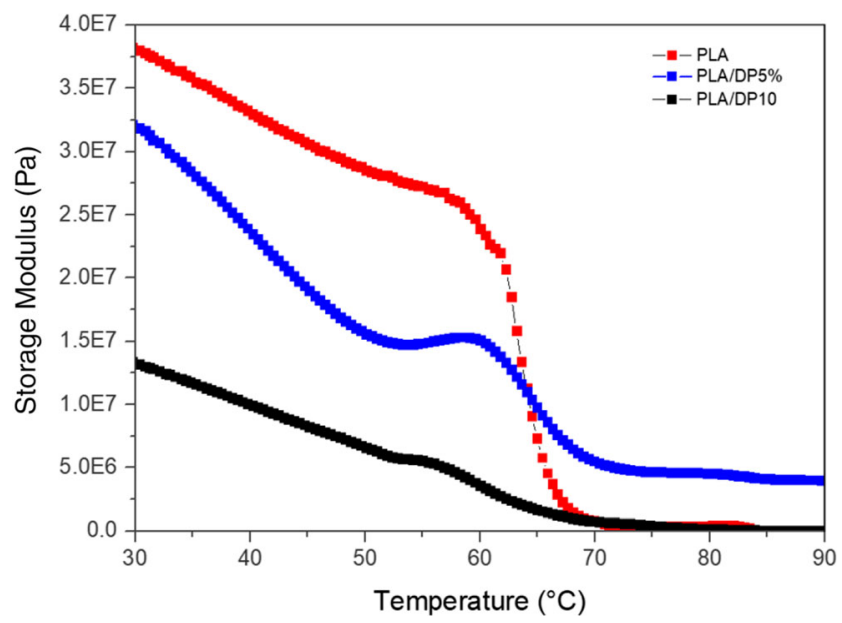

Fig. 3 Storage modulus vs. temperature for pure PLA and its blended systems

polyphenol and the carbonyl groups of the polylactic acid. The dynamic storage modulus $(E)$ is defined as the stress in phase with the strain in a sinusoidal shearing deformation divided by the strain [25]. The variation in the storage modulus as a function of temperature for the studied blends is illustrated in Fig. 3. As the temperature increases, the plateau region drops rapidly due to the increase in molecular mobility of the polymer chains at the Tg, indicating that the scaffold become more plasticized having easier mobility [26].

\subsection{Cell proliferation}

As a strategy to determine the cytocompatibility of PLA and PLA/DP scaffolds, we performed cell proliferation studies using 3 T3 fibroblast cell line as explained in Fig. 5. MTT assay was used for this purpose and the result is shown in Fig. 6. As expected, the proliferation of cells grown in the presence of PLA scaffold was comparable with those grown

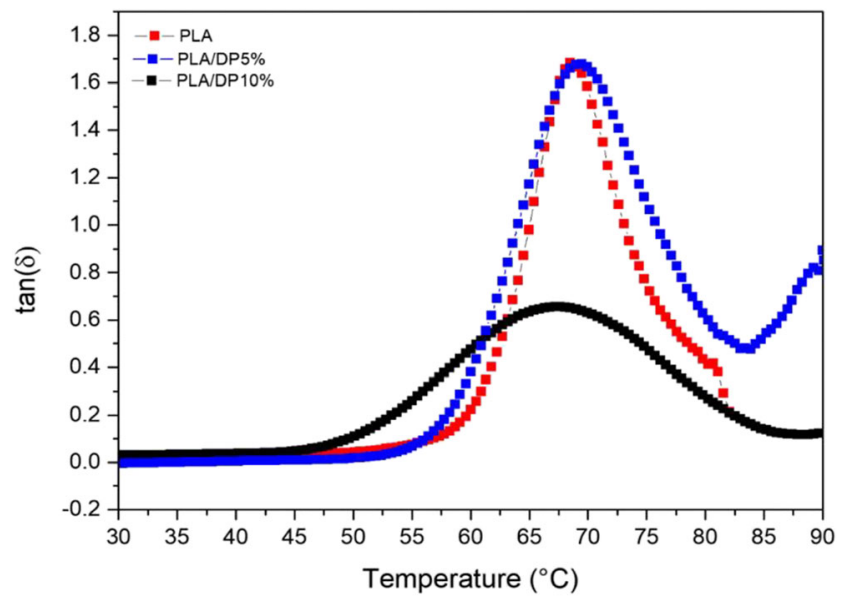

Fig. 4 Tan $\delta$ vs. temperature for pure PLA and its blended systems 
Fig. 5 Schematic illustration of the mechanism of cell proliferation on PLA/polyphenol nanofibre scaffolds

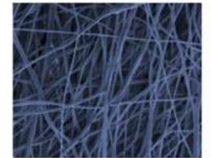

PLA fiber scaffold
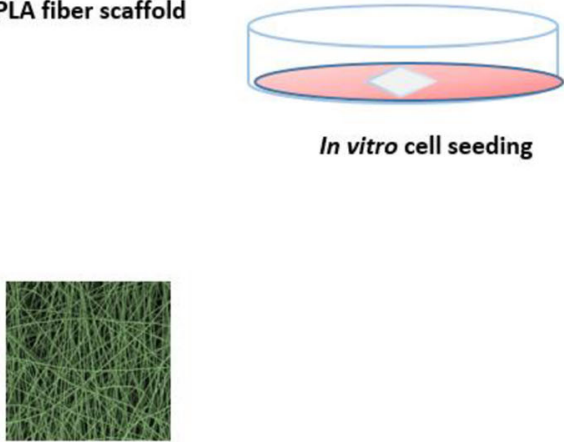

PLA / Polyphenol fiber scaffold

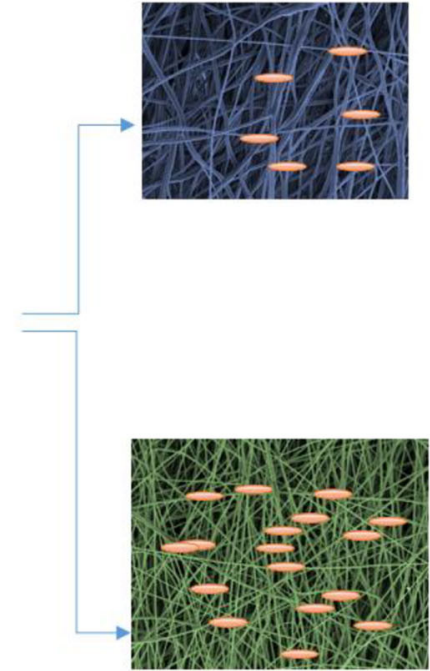

cell proliferation on bare cell culture plates. After $24 \mathrm{~h}$ of cell culture, the viability of cells cultured with pure PLA membranes was $100.2 \pm$ $4.9 \%$. Proliferation of cells grown in the presence of PLA/DP5 scaffolds was $115.4 \pm 1.4 \%$. Cell proliferation was much higher for cells cultured with PLA/DP10 scaffolds (124.0 1.7). Scaffolds loaded with DP10 showed the highest set of viability results compared with the bare PLA and controls $(P \leq 0.05)$ investigated in this study.

\subsection{Cell viability}

Direct visualization of viable cells is important in TE to evaluate the effect of scaffold conditions on cell behaviour. Cultured fibroblasts were cultured in the presence of pure

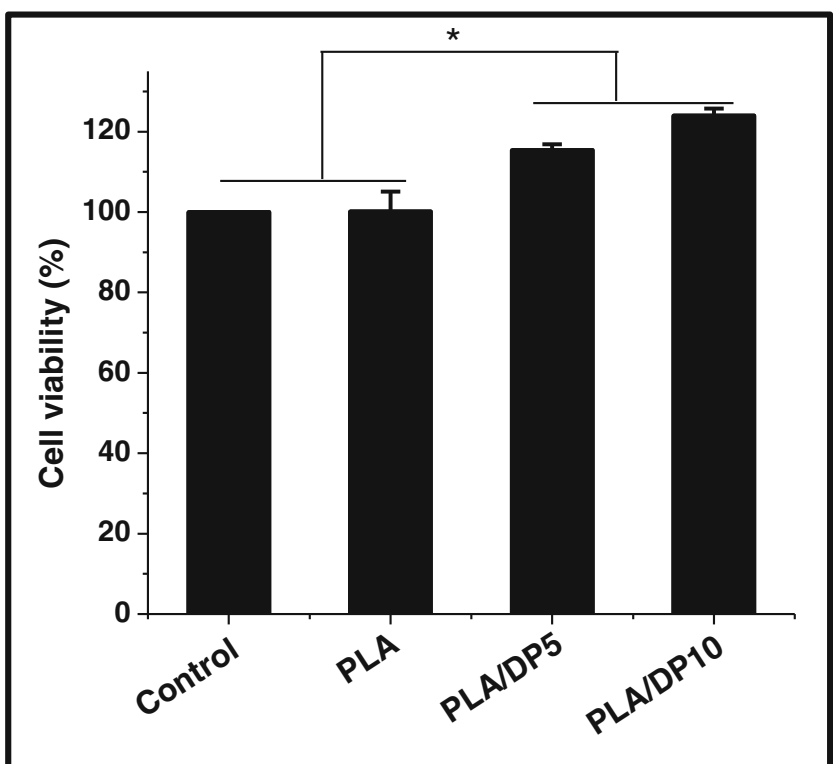

Fig. 6 Proliferation of 3T3 fibroblast cells in the presence of PLA and PLA/DP scaffolds
PLA or PLA/polyphenol scaffolds and then were stained with a live/dead assay, where live cells fluoresce green and dead cells fluoresce red. As shown in Fig. 7, both the control and PLA scaffold-treated groups showed relatively similar number of live and dead cells. The percentage of green fluorescent (live cells) was higher in PLA/DP5 scaffold treatment groups compared with the PLA scaffold groups. Very interestingly, in the PLA/DP10-treated cells, most cells were green, indicating the highest set of viability and cell proliferation. These results suggest that the DP incorporation in PLA scaffolds helped to improve the cell viability and cell proliferation of seeded 3T3 fibroblasts. However, we did not observe considerable variation in relative ratio of live and dead cells, which indicate the nontoxicity of all the tested scaffolds irrespective of DP content.

In support to our results, earlier studies demonstrated that PLA-based scaffolds do not elicit any cytotoxic effects on human foetal osteoblasts cells [27]. Another interesting study indicated that PLA nanofibre scaffolds could improve the mineralization rate of stem cells isolated from human exfoliated deciduous teeth [28]. The increased cell viability and proliferation upon treatment with electrospun PLA/DP scaffolds might be because of the improved hydrophilicity of the scaffolds due to the presence of polyphenol. Increased hydrophilicity in cell culture scaffolds is expected to enhance cell proliferation as shown in previous studies from our group [29, 30]. It is known that cells prefer to grow on moderately hydrophilic surfaces, since it enables the polymer to adsorb cell adhesion proteins $[31,32]$. In addition to that, the released polyphenol from the scaffolds might have played an active role in improving cell viability and proliferation. Earlier reports suggest that antioxidant property of polyphenol can minimize ROS-induced cell damage and improve cell viability [33]. In summary, the present study provides a proof of concept for the ability of polyphenol to enhance cell viability and 
Fig. 7 Live/dead assay on NIH/ $3 \mathrm{~T} 3$ cells treated with PLA, PLA/ DP5 and PLA/DP10 (a).

Quantification of viable cells from live/dead assay (b)

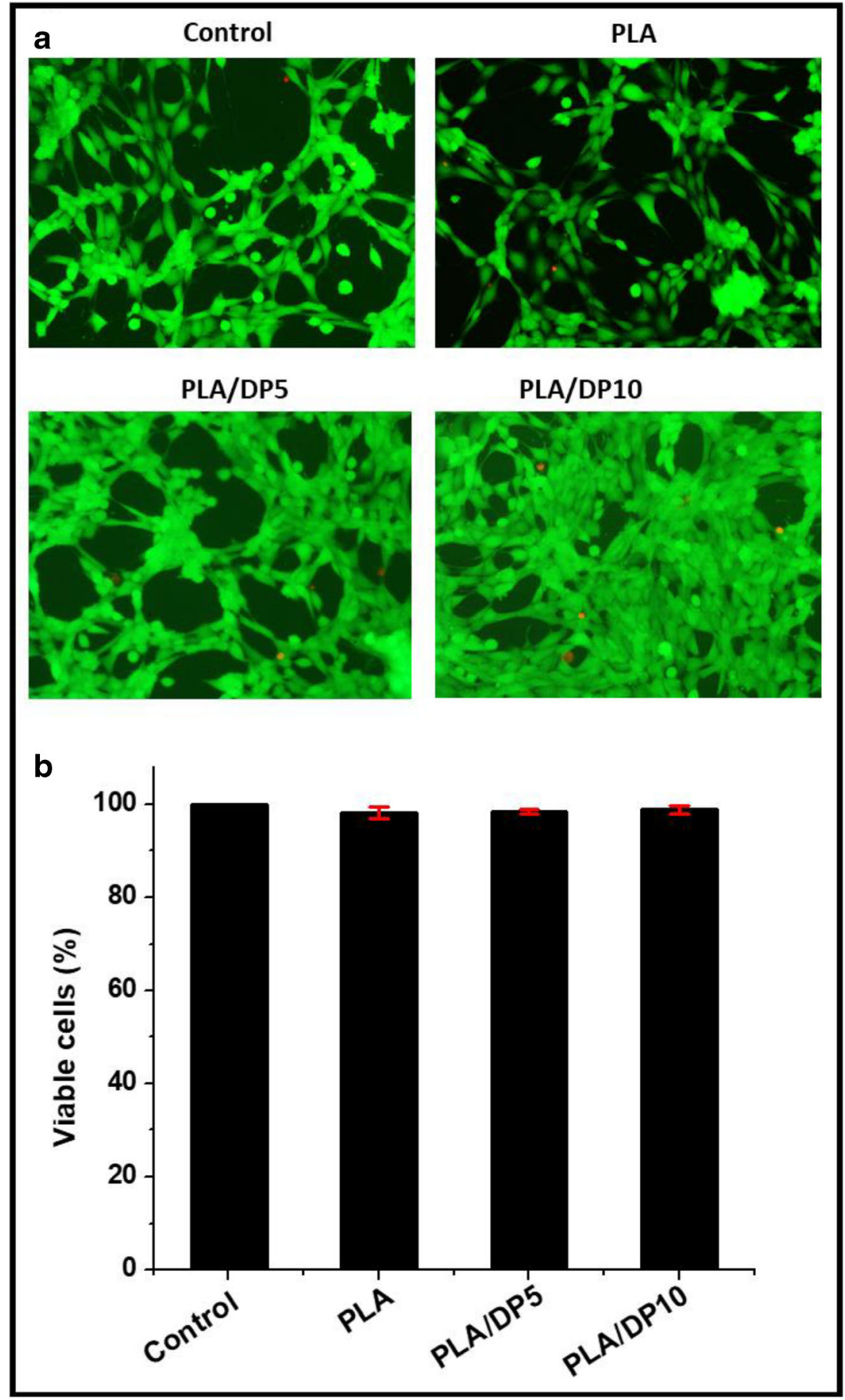

proliferation of fibroblast cells, which will have potential applications in tissue engineering and wound healing.

\subsection{Cell migration}

The wound healing scratch test can be used to understand the effect of wound coverage materials to accelerate or decelerate the healing of wounds in vitro [34]. The scratch assay results obtained using the scratch test are given in Fig. 8. After $24 \mathrm{~h}$ of treatment with the scaffold, about $20 \%$ of scratched area was healed in control due to the migration of $3 \mathrm{~T} 3$ cells into the scratched area. Relatively similar trend was observed on the PLA membranes. In contrast, both PLA/DP5 and PLA/DP10 scaffold groups considerably enhanced the scratch healing compared with the pure PLA scaffolds and control groups. Overall, it has been observed that polyphenol-containing PLA scaffolds improved the cell migration for the in vitro wound model.

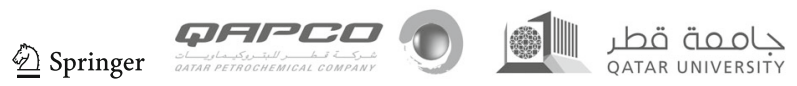


Fig. 8 In vitro wound healing assay using $3 \mathrm{~T} 3$ cells.

Microscopic images showing the scratched area at the beginning of experiment $(0 \mathrm{~h})$ and after $24 \mathrm{~h}$
It has been previously observed that tea polyphenols loaded in chitosan scaffolds improved in vivo wound healing [35]. Further, biomolecules from date palm might also have played some role in wound healing in a similar manner [36]. In wounds, over-expression of proinflammatory cytokines might affect cellular functions and would retard the natural process of cell migration and wound healing [37]. Developed scaffolds incorporated with antioxidant DP could minimize the oxidative stress and subsequently promote healing process. However, detailed in vivo studies need to be performed to fully verify the wound healing potential of the developed scaffolds in animal models. Our future investigations will focus on such in vivo wound healing studies and the histological analysis of excised skin from the healed wound area.

\section{Conclusion}

In this study, we aimed to demonstrate the potential benefits of incorporating polyphenol extracted from date palm fruit in
PLA scaffolds for TE applications. For this purpose, PLA scaffolds loaded with various concentrations of polyphenol were produced via electrospinning. Structural and mechanical characterizations were studied via SEM, contact angle, tensile testing and DMA. SEM revealed that the fibre diameter decreased, whereas the porosity of the scaffold increased with increased polyphenol content within the PLA matrix, suggesting enhanced cell culture characteristics of PLA/polyphenol scaffolds.

In vitro cell culture studies using NIH/3T3 fibroblast cells showed that the scaffolds were biocompatible and supported cell adhesion, particularly when the content of the polyphenols increased. The enhanced cell adhesion was attributed to the increased hydrophilicity of the polyphenol scaffolds. The surface tension of the scaffolds was assessed by analyzing the contact angle. The results showed that blend of PLA/DP scaffolds had higher hydrophilicities compared with hydrophobic PLA matrix. Thus, the enhancement in cell proliferation and cell viability and the increased cell migration through the scratch with higher loading of polyphenols were attributed

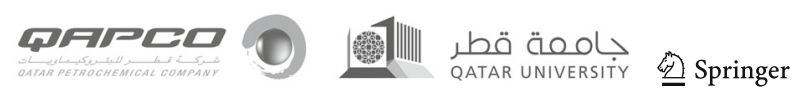


to increased hydrophilicity. In summary, in this study, we demonstrated the potential utilization of PLA/polyphenol scaffolds for TE applications such as regeneration of damaged tissue or wound healing assays.

Funding information Open access funding provided by Qatar National Library. K. M. Zadeh received financial support from the Center for Advanced Materials, Qatar University, throughout this work.

\section{Compliance with ethical standards}

Conflict of interest The authors declare that they have no conflict of interest.

Open Access This article is distributed under the terms of the Creative Commons Attribution 4.0 International License (http:// creativecommons.org/licenses/by/4.0/), which permits unrestricted use, distribution, and reproduction in any medium, provided you give appropriate credit to the original author(s) and the source, provide a link to the Creative Commons license, and indicate if changes were made.

\section{References}

1. I. Rajzer, E. Menaszek, O. Castano, Electrospun polymer scaffolds modified with drugs for tissue engineering. Mater Sci Eng C Mater Biol Appl 77, 493-499 (2017)

2. S. Nandagopal et al., Gentamicin loaded electrospun poly (epsiloncaprolactone)/TiO2 nanocomposite membranes with antibacterial property against methicillin resistant Staphylococcus aureus. Polym-Plast Technol Eng 55(17), 1785-1796 (2016)

3. S.G. Kumbar, S.P. Nukavarapu, R. James, L.S. Nair, C.T. Laurencin, Electrospun poly (lactic acid-co-glycolic acid) scaffolds for skin tissue engineering. Biomaterials 29(30), 4100-4107 (2008)

4. C.Y. Cheung, S.J. McCartney, K.S. Anseth, Synthesis of polymerizable superoxide dismutase mimetics to reduce reactive oxygen species damage in transplanted biomedical devices. Adv Funct Mater 18, 3119-3126 (2008)

5. G. Waris, H. Ahsan, Reactive oxygen species: role in the development of cancer and various chronic conditions. J Carcinog 5, 14 (2006)

6. R. Augustine, Electrospun polycaprolactone (PCL) scaffolds embedded with europium hydroxide nanorods (EHNs) with enhanced vascularization and cell proliferation for tissue engineering applications. J Mater Chem B 5, 4660-4672 (2017)

7. M.M. Pillai, J. Gopinathan, R. Senthil Kumar, G. Sathish Kumar, S. Shanthakumari, K.S. Sahanand, A. Bhattacharyya, R. Selvakumar, Tissue engineering of human knee meniscus using functionalized and reinforced silk-polyvinyl alcohol composite three-dimensional scaffolds: understanding the in vitro and in vivo behavior. J Biomed Mater Res B Appl Biomater 106, 1722-1731 (2018)

8. R. Kumari, P.K. Dutta, Physicochemical and biological activity study of genipin-crosslinked chitosan scaffolds prepared by using supercritical carbon dioxide for tissue engineering applications. Int J Biol Macromol 46, 261-266 (2010)

9. R. Augustine, P. Dan, A. Sosnik, N. Kalarikkal, N. Tran, B. Vincent, S. Thomas, P. Menu, D. Rouxel, Electrospun poly (vinylidene fluoride-trifluoroethylene)/zinc oxide nanocomposite tissue engineering scaffolds with enhanced cell adhesion and blood vessel formation. Nano Res 10(10), 3358-3376 (2017)

10. E. Llorens, L.J. del Valle, A. Díaz, M.T. Casas, J. Puiggalí, Polylactide nanofibers loaded with vitamin B6 and polyphenols as bioactive platform for tissue engineering. Macromol Res 21(7), 775-787 (2013)

11. C. Mohanty, S.K. Sahoo, Curcumin and its topical formulations for wound healing applications. Drug Discov Today 22, 1582-1592 (2017)

12. K.B. Pandey, S.I. Rizvi, Plant polyphenols as dietary antioxidants in human health and disease. Oxidative Med Cell Longev 2(5), 270 278 (2009)

13. X. Pan, G. Niu, H. Liu, Microwave-assisted extraction of tea polyphenols and tea caffeine from green tea leaves. Chem Eng Process Process Intensif 42, 129-133 (2003)

14. G.-F.D. En-Qin Xia, Y.-J. Guo, H.-B. Li, Biological activities of polyphenols from grapes. Int J Mol Sci 11, 622-646 (2010)

15. Y. Fei, Preparation and charectarization of antibactirial PLA/TP nanofiber. Fiber Polym 12(3), 340-344 (2011)

16. D. Amal Daoud, S. Bakari, Assessment of polyphenol composition, antioxidant and antimicrobial properties of various extracts of date palm pollen (DPP) from two Tunisian cultivars. Arab J Chem (2015)

17. K.M. Zadeh, I.M. Inuwa, R. Arjmandi, A. Hassan, M. Almaadeed, Z. Mohamad, P.N. Khanam, Effects of date palm leaf fiber on the thermal and tensile properties of recycled ternary polyolefin blend composites. Fiber Polym 18(7), 1330-1335 (2017)

18. V. Basak et al., Evaluation of cytotoxicity and gelatinases activity in 3 T3 fibroblast cell by root repair materials. Biotechnology \& Biotechnological Equipment 30(5), 984-990 (2016)

19. V. Mitran et al., Dose-related effects of sericin on preadipocyte behavior within collagen/sericin hybrid scaffolds. Progress in Natural Science: Materials International 25(2), 122-130 (2015)

20. F. Biglari, A.F.M. AlKarkhi, A.M. Easa, Antioxidant activity and phenolic content of various date palm (Phoenix dactylifera) fruits from Iran. Food Chem 107(4), 1636-1641 (2008)

21. J.M. Deitzel, J. Kleinmeyer, D.E.A. Harris, N.B. Tan, The effect of processing variables on the morphology of electrospun nanofibers and textiles. Polymer 42(1), 261-272 (2001)

22. Y. Fei, Y. Chen, H. Wang, W. Gao, R. Yang, Y. Wan, Preparation, characterization of antibacterial PLA/TP nanofibers. Fibers and Polymers 12(3), 340-344 (2011)

23. Y. Liu, X. Liang, S. Wang, W. Qin, Q. Zhang, Electrospun antimicrobial polylactic acid/tea polyphenol nanofibers for foodpackaging applications. Polymers 10(5), 561 (2018)

24. H.L. Ornaghi Jr, A.S. Bolner, R. Fiorio, A.J. Zattera, S.C. Amico, Mechanical and dynamic mechanical analysis of hybrid composites molded by resin transfer molding. J Appl Polym Sci 118(2), 887896 (2010)

25. M. Rahail Parvaiz, P.V. Thorat, P.A. Mahanwar, Dynamic mechanical analysis and morphological studies of fly ash/mica reinforced poly (ether-ether-ketone)-based hybrid composites. Polym Compos 35(1), 68-78 (2014)

26. I. Pillin, Thermo-mechanical characterization of plasticized PLA: Is the miscibility the only significant factor. Polymer 47, 4676-4682 (2006)

27. M.C. Wurm, T. Möst, B. Bergauer, D. Rietzel, F.W. Neukam, S.C. Cifuentes, C. Wilmowsky, In-vitro evaluation of Polylactic acid (PLA) manufactured by fused deposition modeling. J Biol Eng 11, 29 (2017)

28. X. Wang, G. Li, Y. Liu, W. Yu, Q. Sun, Q, Biocompatibility of biological material polylactic acid with stem cells from human exfoliated deciduous teeth. Biomedical reports 6(5), 519-524 (2017)

29. R. Augustine, E.A. Dominic, I. Reju, B. Kaimal, N. Kalarikkal, S. Thomas, Electrospun poly (epsilon-caprolactone)-based skin substitutes: In vivo evaluation of wound healing and the mechanism of cell proliferation. J Biomed Mater Res B Appl Biomater 103(7), 1445-1454 (2015)

30. R. Augustine, A. Saha, V.P. Jayachandran, S. Thomas, N. Kalarikkal, Dose-dependent effects of gamma irradiation on the 
materials properties and cell proliferation of electrospun polycaprolactone tissue engineering scaffolds. Int J Polym Mater Polym Biomater 64(10), 526-533 (2015)

31. G. Altankov, F. Grinnell, T. Groth, Studies on the biocompatibility of materials: fibroblast reorganization of substratum-bound fibronectin on surfaces varying in wettability. J Biomed Mater Res 30(3), 385-391 (1996)

32. Z. Ma, Z. Mao, C. Gao, Surface modification and property analysis of biomedical polymers used for tissue engineering. Colloids Surf B: Biointerfaces 60(2), 137-157 (2007)

33. A. Shirai et al., Effect of polyphenols on reactive oxygen species production and cell growth of human dermal fibroblasts after irradiation with ultraviolet-A light. Biocontrol Sci 20(1), 27-33 (2015)
34. C.C. Liang, A.Y. Park, J.L. Guan, In vitro scratch assay: a convenient and inexpensive method for analysis of cell migration in vitro. Nat Protoc 2, 329-333 (2007)

35. Y. Qin et al., Chitosan green tea polyphenol complex as a released control compound for wound healing. Chin J Traumatol 13, 91-95 (2010)

36. P. Vayalil, Antioxidant and antimutagenic properties of aqueous extract of date fruit (Phoenix dactylifera L. arecaceae). J Agric Food Chem 50, 610-617 (2002)

37. C.K. Sen, S. Khanna, G. Gordillo, D. Bagchi, M. Bagchi, S. Roy, Oxygen, oxidants, and antioxidants in wound healing: an emerging paradigm. Annal NY Acad Sci 957(1), 239-249 (2002) 